\title{
Shift work and metabolic syndrome: A multi-center cross-sectional study on females of reproductive age
}

\author{
MARYAM NIKPOUR ${ }^{1}$, ARAM TIRGAR ${ }^{2}$, MAHMOD HAJIAHMADI $^{3}$, AKRAM HOSSEINI $^{4}$, \\ BEHZAD HEIDARI $^{5}$, FATEMEH GHAFFARI ${ }^{6}$, ABBAS EBADI $^{7}$, \\ FATEMEH NASIRI-AMIRI $^{8}$ and MOJGAN FIROUZBAKHT ${ }^{1}$
}

\begin{abstract}
${ }^{1}$ Student Research Committee, Health Research Institute, Babol University of Medical Sciences, Babol 47745-47176;
${ }^{2}$ Social Determinants of Health Research Center, Health Research Institute, Babol University of Medical Sciences,

Babol 47745-47176; ${ }^{3}$ Department of Biostatistics, Non Communicable Pediatric Disease Research Center,

Health Research Institute, Babol 47745-47176; ${ }^{4}$ Clinical Research Development Center, Shahid Beheshti Hospital, Babol University of Medical Sciences, Babol 47745-47176; ${ }^{5}$ Mobility Impairment Research Center, Health Research Institute, Babol University of Medical Sciences, Babol 47745-47176; ${ }^{6}$ Nursing Care Research Center, Health Research Institute, Babol University of Medical Sciences, Babol 47745-47176; ${ }^{7}$ Behavioral Sciences Research Center, Life Style Institute, Faculty of Nursing, Baqiyatallah University of Medical Sciences, Tehran 14359-16471; ${ }^{8}$ Infertility and Health Reproductive Research Center, Health Research Institute, Babol University of Medical Sciences, Babol 47745-47176, Iran
\end{abstract}

Received February 14, 2019; Accepted April 1, 2019

DOI: $10.3892 /$ br.2019.1205

\begin{abstract}
Shift work during reproductive age can be a risk factor for metabolic syndrome. The present study evaluated the association between shift work and metabolic syndrome during reproductive age. This multi-center cross-sectional correlational study was performed between September 2017 and May 2018. A total of 419 female shift and day workers were purposively recruited to the study from three central cities in Mazandaran, Iran. To diagnose metabolic syndrome based on the National Cholesterol Education Program Adult Treatment Panel III guidelines, the anthropometric measures, blood pressure, and levels of serum triglyceride, high-density lipoprotein and fasting blood sugar were taken. Data were analyzed using the independent-sample t, Chi-square and the Fisher's exact tests as well as the logistic regression analysis. Among the 419 participants, 28 were excluded during the study. The total prevalence of metabolic syndrome was $16.3 \%$, and its prevalence among shift workers and day workers was 17.3 and $14.9 \%$, respectively. The most prevalent components of metabolic syndrome were low serum level of high-density lipoprotein and abdominal obesity. Following adjustments for the effects of potential cofounders, the logistic regression analysis revealed that the odds of metabolic syndrome among
\end{abstract}

Correspondence to: Dr Aram Tirgar, Social Determinants of Health Research Center, Health Research Institute, Babol University of Medical Sciences, Ganjafrooz Street, Babol 47745-47176, Iran E-mail: a.tirgar@mubabol.ac.ir

Key words: metabolic syndrome, shift work, female shift workers, reproductive age shift workers was $\sim 2$ times greater than day workers (odds ratio, 1.83; 95\% confidence interval, 0.088-3.79), although this association was statistically insignificant $(\mathrm{P}=0.10)$. The results of the current study suggest that shift work is associated with a greater risk of metabolic syndrome for women. The most important components of metabolic syndrome are low serum level of high-density lipoprotein and abdominal obesity, which are attributable to limited physical activity and high occupational stress. The risk of metabolic syndrome among female shift workers of reproductive age may be reduced through strategies, including awareness raising, dietary educations and provision of physical activity facilities in the workplace.

\section{Introduction}

Metabolic syndrome is one of the most important illnesses of the recent century (1). It is a set of symptoms, namely hypertension, dyslipidemia, dysglycemia and abdominal obesity, which occur secondary to insulin resistance (2). Its prevalence is $20.2 \%$ in the United States (3), 30\% in Brazil (4) and $10.7 \%$ in South Korea (5). A meta-analysis on a sample of 74,440 Iranians stated that its prevalence in Iran is $34.7 \%$ (6).

Metabolic syndrome increases the risk of chronic illnesses, particularly cardiovascular disease (7). People with metabolic syndrome are at twice the risk of developing cardiovascular disease, three times the risk of developing ischemic stroke (8), and five times the risk of developing diabetes mellitus (9). Furthermore, those with metabolic syndrome are prone to developing osteoarthritis, certain types of cancer, with increased disability and mortality risks (10). Metabolic syndrome imposes heavy costs on healthcare systems (1).

The pathogenesis of metabolic syndrome remains unclear. It involves a variety of contributing factors, including lifestyle, environmental and genetic factors (11), stress (12), sex (13), 
number of parities (14), and shift work (15). Certain studies have reported a higher risk of metabolic syndrome among women (14) and shift workers (15). Shift work is defined as working night shifts between 6:00 p.m. to 07:00 a.m. It can negatively affect circadian rhythm, and thereby, cause alterations in the secretion of hormones, such as growth hormone, melatonin, cortisol, leptin and ghrelin $(16,17)$. Alterations to these hormones may affect body metabolism, reduce glucose tolerance and increase insulin resistance $(18,19)$. A study on 2,089 hospital staff in South Korea concluded that shift work significantly increases the risk of metabolic syndrome (20). However, certain studies reported an insignificant association with metabolic syndrome $(21,22)$, weight gain $(23)$ and serum lipid levels (24).

In Iran, women are primarily employed in service jobs (25), particularly in hospitals (26), welfare centers (27) and nursing homes, whereby shift work is typically encountered (28). Around two thirds of employed women in Iran are of reproductive age (25), and thus, experience pregnancy and childbirth during their employment (29). Besides shift work, parity and the number of parities can increase the risk of metabolic syndrome among these women due to parity-associated increased abdominal circumference (14) and increased insulin resistance (30). Therefore, female shift workers with more children appear to be at greater risk of developing metabolic syndrome. Previous studies in Iran investigating the association between shift work and metabolic syndrome have been performed on industrial workers (24) and drivers (7). However, to the best of our knowledge, no study has yet evaluated the prevalence of metabolic syndrome among Iranian female shift workers, particularly those who are married and are of reproductive age. The current study aimed to evaluate the association between shift work with metabolic syndrome during reproductive age.

\section{Materials and methods}

Patients. The present multi-center cross-sectional correlational study was performed between September 2017 and May 2018 in three central cities located in Mazandaran, Iran (Amol, Babol and Ghaemshahr). Participants were female shift and day workers purposively selected from hospitals, welfare and rehabilitation centers, nursing homes, and textile and sewing mills. Participants were recruited if they were between 18 and 45 years old, married and had $>2$ years of work experience. The exclusion criteria maintained were voluntary withdrawal from the study or incompletion of the study, and having cardiovascular disease, diabetes mellitus, or hypertension (with a blood pressure of $>140 / 90 \mathrm{mmHg}$ ) at the beginning of work.

For sample size calculation, the prevalence of metabolic syndrome was considered to be at most $25 \%$ based on results from two previous studies $(31,32)$. Accordingly, with a confidence level of $95 \%$ and an estimation error of $6 \%$, the sample size was estimated to be 200 participants/group. Yet, considering an attrition rate of 5\%, 419 women were selected.

Assessment of demographical, occupational and medical characteristics. A questionnaire was used to assess participant demographical, occupational and reproductive characteristics. Demographical characteristics included age, educational level, place of residence and family income. Occupational charac- teristics were work schedule (shift work or day work), work experience, number of working hours/month, organizational position, workload and occupational stress. Workload was assessed using a question answered on a five-point Likert scale from 'light' to 'heavy', while occupational stress was assessed using a question answered on a five-point Likert scale from 'very low' to 'very high'. Reproductive characteristics assessed in the present study were number of parities and route of delivery.

Assessment of health-associated behaviors. Participant health-associated behaviors were assessed through questions regarding cigarette smoking (yes/no), alcohol consumption (yes/no), sleep quantity and quality, and physical activity. The questions for sleep quantity and quality assessment were, 'How many hours do you sleep a day, on average?' and 'Is your current sleep adequate to fulfil your need for sleep?' (yes/no), respectively. For physical activity assessment, participants were asked if they walked $\geq 30$ min thrice weekly. 'Yes' and 'No' responses to this question were respectively interpreted as physically active and physically inactive.

Anthropometric measures. An analogue weight scale (MW84; EmsiG GmbH Co., Hamburg, Germany) and a wall-mounted plastic tape were used to respectively measure weight and height in upright position without shoes and with minimum possible clothes. Waist circumference (WC) was also measured in the midway between the lowest rib edge and the iliac crest.

Blood pressure. Blood pressure (BP) was measured using an analogue sphygmomanometer (EmsiG GmbH Co.) from the right arm in the sitting position, and following a 15-min rest.

Biomarkers. Biomarkers assessed in the current study were triglyceride (TG), high-density lipoprotein (HDL) and fasting blood sugar (FBS). Accordingly, a 5-mm blood sample was taken from each participant at 07:00-09:00 a.m. following a night time fasting period of 12-14 h. Subsequently, biochemical analysis was performed in a laboratory of a hospital affiliated to Babol University of Medical Sciences, Babol, Iran. All laboratory analyses were performed by a laboratory technician, using an identical kit (Pars Azmoon kit, Pars Azmoon Inc., Tehran, Iran), and one biochemistry analyzer (Sapphire 800; Audit Diagnostics, Cork, Ireland). Furthermore, blood sampling and anthropometric and blood pressure measurements were performed by one person.

Diagnostic criteria for metabolic syndrome. According to the National Cholesterol Education Program Adult Treatment Panel III guidelines (33), participants were diagnosed with metabolic syndrome if they simultaneously met three of the following five criteria: i) Hypertension as determined by a $\mathrm{BP}$ $>130 / 85 \mathrm{mmHg}$ or taking blood pressure medications; ii) high serum TG level (>150 mg/dl); iii) high FBS (>110 mg/dl); iv) low serum HDL level ( $<50 \mathrm{mg} / \mathrm{dl})$; and v) abdominal obesity as determined by a $\mathrm{WC}$ of $>88 \mathrm{~cm}$.

Shift work assessment. Participants were divided into two main groups based on the work schedules, day workers and shift workers. Participants who did morning or evening shifts and never did night shift were considered as day workers. Shift 


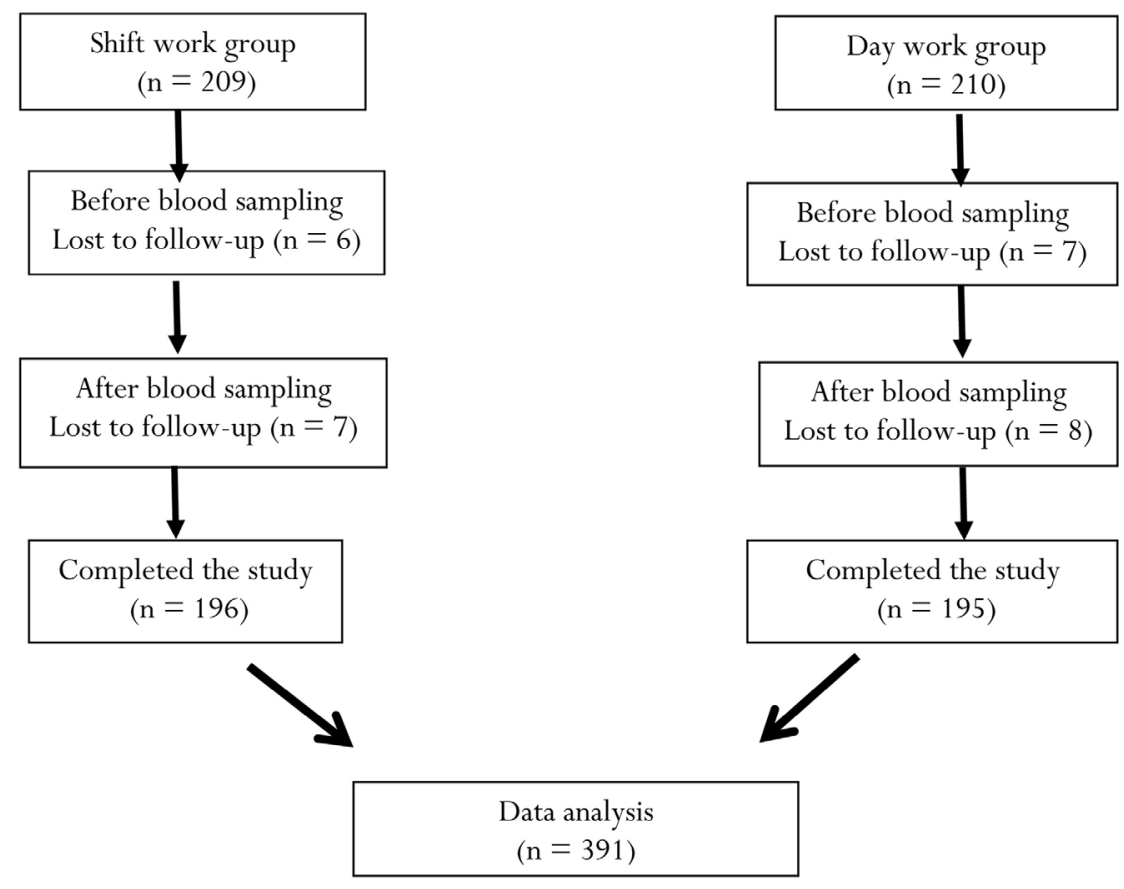

Figure 1. Flow diagram of the experimental study design.

workers included participants who had rotational work. Shift workers were those participants who worked 3 shifts of $8 \mathrm{~h}$ (morning, evening and night shifts) or who worked two shifts of $8 \mathrm{~h}$ and one of $12 \mathrm{~h}$ or who worked 2 shifts of $12 \mathrm{~h}$.

Statistical data analysis. The data were analyzed using SPSS (version 16.0; SPSS, Inc., Chicago, IL, USA). Shift worker and day worker participants were compared with each other respecting their demographical, occupational, and reproductive characteristics and health-associated behaviors using the independent-sample t, Chi-square and the Fisher's exact tests. Furthermore, logistic regression analysis was performed to determine the effect of shift work on the odds of metabolic syndrome following adjustments for the effects of potential confounders. For regression analysis, the variable number of sleeping hours was dichotomized as ' $<6 \mathrm{~h}$ ' and ' $>6$ h'. $\mathrm{P}<0.05$ was considered to indicate a statistically significant difference.

\section{Results}

Participants' demographical, occupational and reproductive characteristics. Among the 419 women recruited to the study, 28 were excluded due to voluntary withdrawal or study incompletion. Consequently, statistical data analysis was performed on the data collected from 391 participants (Fig. 1). A total of 196 shift workers and 195 day workers were included. Those who were excluded from the study did not significantly differ from participants respecting their demographical, occupational and reproductive characteristics $(\mathrm{P}>0.05)$.

The mean age and work experience of participants were $36.12 \pm 5.21$ and $12.38 \pm 5.92$ years, respectively, and there was no statistically significant difference between shift workers and day workers in terms of age and work experience. Shift workers had significantly higher levels of Monthly work (h) compared with day workers. ( $\mathrm{P}<0.001 ; 192.61 \pm 23.33$ vs. $179.12 \pm 18.76$ ).

The majority of participants held university degrees (73\%), resided in urban areas $(84 \%)$, were a healthcare provider (70\%), had a heavy workload with high levels of occupational stress $(60 \%)$, and had given birth through a caesarean section (70\%). Approximately $50 \%$ of women had one child (49.5\%). Shift workers had significantly higher levels of occupational stress compared with day workers $(\mathrm{P}=0.02)$ and participants with more parities had significantly greater WC measures $(\mathrm{P}<0.001)$.

Participants' health-associated behaviors. One third of participants $(33.3 \%)$ were physically active, $2 \%$ of them smoked cigarettes and none reported alcohol consumption. Furthermore, $48 \%$ of participants reported having inadequate sleep. Sleep adequacy among shift workers was significantly reduced compared with day workers $(\mathrm{P}=0.006$; Table I). In addition, the length of sleep in a 24 -h period among shift workers was significantly shorter compared with day workers $(\mathrm{P}<0.001)$.

Association between shift work and metabolic syndrome. The total prevalence of metabolic syndrome was $16.3 \%$. The rate among shift workers and day workers was 17.3 and $14.9 \%$, respectively, with no statistically significant between-group difference $(\mathrm{P}=0.50$; Table II). The most prevalent components of metabolic syndrome among participants were low serum HDL level (88\%) and abdominal obesity (73\%). The prevalence of low serum HDL level among shift workers was significantly increased compared with day workers $(\mathrm{P}=0.019)$. However, they did not significantly differ from each other respecting the other components of metabolic syndrome, including hypertension, dysglycemia, abdominal obesity and hypertriglyceridemia ( $\mathrm{P}>0.05$; Table II). 
Table I. Participants' demographical, occupational and reproductive characteristics.

\begin{tabular}{|c|c|c|c|c|}
\hline Characteristics & $\begin{array}{l}\text { Total } \\
\mathrm{N}(\%)\end{array}$ & $\begin{array}{l}\text { Shift workers } \\
\text { N }(\%)\end{array}$ & $\begin{array}{c}\text { Day workers } \\
\text { N }(\%)\end{array}$ & P-value \\
\hline Age (years) & & & & $0.26^{\mathrm{a}}$ \\
\hline $20-29$ & $46(11.8)$ & $27(13.8)$ & $19(9.7)$ & \\
\hline $30-39$ & $222(55.9)$ & $113(57.9)$ & $109(55.9)$ & \\
\hline $40-45$ & $122(31.3)$ & $55(28.2)$ & $67(34.4)$ & \\
\hline Educational level & & & & $0.82^{\mathrm{a}}$ \\
\hline Bachelor's & $287(8.73)$ & $146(75.3)$ & $141(72.3)$ & \\
\hline Diploma & $72(18.5)$ & $34(17.5)$ & $38(19.5)$ & \\
\hline Incomplete secondary & $87(13.3)$ & $14(4.2)$ & $16(8.2)$ & \\
\hline Place of residence & & & & $0.20^{\mathrm{a}}$ \\
\hline Urban areas & $61(15.7)$ & $35(18.0)$ & $26(13.3)$ & \\
\hline Rural areas & $328(84.3)$ & $159(82.0)$ & $169(86.7)$ & \\
\hline Family income & & & & $0.036^{\mathrm{a}}$ \\
\hline Sufficient & $149(40.38)$ & $63(32.5)$ & $86(44.3)$ & \\
\hline Moderately sufficient & $179(46.1)$ & $95(49.0)$ & $84(43.3)$ & \\
\hline Insufficient & $60(15.5)$ & $36(18.6)$ & $24(12.4)$ & \\
\hline Body mass index $\left(\mathrm{kg} / \mathrm{m}^{2}\right)$ & & & & $0.27^{\mathrm{a}}$ \\
\hline$<18.5$ & $2(0.5)$ & $2(0.6)$ & $0(0.0)$ & \\
\hline $18.5-25$ & $131(33.5)$ & $69(35.2)$ & $62(31.8)$ & \\
\hline $25-30$ & $176(45.0)$ & $81(41.3)$ & $95(48.7)$ & \\
\hline$>30$ & $82(21.0)$ & $44(22.4)$ & $38(19.5)$ & \\
\hline Number of parities & & & & $0.64^{\mathrm{a}}$ \\
\hline 1 & $185(49.6)$ & $91(48.4)$ & $94(50.8)$ & \\
\hline$\geq 2$ & $188(50.4)$ & $97(51.6)$ & $91(49.2)$ & \\
\hline Route of delivery & & & & $0.46^{\mathrm{a}}$ \\
\hline Normal vaginal delivery & $109(29.8)$ & $50(27.0)$ & $59(32.6)$ & \\
\hline Cesarean section & $234(63.9)$ & $122(65.9)$ & $112(61.9)$ & \\
\hline Both (in different deliveries) & $23(6.3)$ & $13(7.0)$ & $10(5.5)$ & \\
\hline Physical activity & & & & $0.057^{\mathrm{a}}$ \\
\hline Inactive & $143(38.3)$ & $61(33.3)$ & $82(43.2)$ & \\
\hline Active & $230(61.7)$ & $122(66.7)$ & $108(56.8)$ & \\
\hline Cigarette smoking & & & & $0.68^{\mathrm{b}}$ \\
\hline Yes & $5(1.3)$ & $2(1.0)$ & $3(1.5)$ & \\
\hline No & $611(98.1)$ & $125(97.7)$ & $477(98.1)$ & \\
\hline Sleep adequacy (h/day) & & & & $0.006^{\mathrm{a}}$ \\
\hline Inadequate & $180(48.0)$ & $103(55.1)$ & $77(41.0)$ & \\
\hline Adequate & $195(52.0)$ & $84(44.9)$ & $111(59.0)$ & \\
\hline Employment status & & & & $0.17^{\mathrm{a}}$ \\
\hline Healthcare provider & $273(70.7)$ & $136(69.4)$ & $137(72.1)$ & \\
\hline Mother aid or nurse aid & $61(15.7)$ & $38(19.4)$ & $23(12.1)$ & \\
\hline Laborer & $34(8.8)$ & $15(7.7)$ & $19(10.0)$ & \\
\hline Service worker & $18(4.7)$ & $7(3.6)$ & $11(5.8)$ & \\
\hline Workload & & & & $0.14^{\mathrm{a}}$ \\
\hline Low to moderate & $151(39.6)$ & $67(35.3)$ & $84(44.0)$ & \\
\hline Heavy & $161(42.3)$ & $83(43.7)$ & $78(40.8)$ & \\
\hline Very heavy & $69(18.1)$ & $40(21.1)$ & $29(15.2)$ & \\
\hline Occupational stress & & & & $0.002^{\mathrm{a}}$ \\
\hline Very high & $66(17.3)$ & $43(22.6)$ & $23(12.0)$ & \\
\hline High & $138(36.1)$ & $74(38.9)$ & $64(33.3)$ & \\
\hline Low to moderate & $178(46.6)$ & $73(38.4)$ & $105(54.7)$ & \\
\hline
\end{tabular}

${ }^{a}$ The results of the Chi-square test; ${ }^{\text {b}}$ The results of the Fisher's exact test. SD, standard deviation. 
Table II. Prevalence of metabolic syndrome and its components among shift and day workers.

\begin{tabular}{|c|c|c|c|c|}
\hline $\begin{array}{l}\text { Metabolic syndrome } \\
\text { and its components }\end{array}$ & $\begin{array}{l}\text { Total } \\
\mathrm{N}(\%)\end{array}$ & $\begin{array}{l}\text { Shift workers } \\
\qquad \mathrm{N}(\%)\end{array}$ & $\begin{array}{l}\text { Day workers } \\
\text { N }(\%)\end{array}$ & P-value ${ }^{a}$ \\
\hline $\mathrm{BP}(\mathrm{mmHg})$ & & & & 0.29 \\
\hline$<130 / 85$ & $377(96.2)$ & $186(94.9)$ & $190(97.4)$ & \\
\hline$\geq 130 / 85$ & $15(3.8)$ & $10(5.1)$ & $5(2.6)$ & \\
\hline FBS (Mg/dl) & & & & 0.47 \\
\hline$<110$ & $384(98)$ & $191(97.4)$ & $192(98.5)$ & \\
\hline$\geq 110$ & $8(2)$ & $5(2.6)$ & $3(1.5)$ & \\
\hline $\mathrm{WC}(\mathrm{cm})$ & & & & 0.42 \\
\hline$<88$ & $105(26.8)$ & $49(25.0)$ & $56(28.7)$ & \\
\hline$\geq 88$ & $287(73.2)$ & $147(75.0)$ & $139(71.3)$ & \\
\hline HDL (Mg/dl) & & & & 0.019 \\
\hline$<50$ & $47(12.0)$ & $16(8.2)$ & $31(15.9)$ & \\
\hline$\geq 50$ & $345(88.0)$ & $180(91.8)$ & $164(84.1)$ & \\
\hline TG (Mg/dl) & & & & 0.73 \\
\hline$<150$ & $314(80.1)$ & $159(81.1)$ & $155(79.5)$ & \\
\hline$\geq 150$ & $78(19.9)$ & $37(18.9)$ & $40(20.5)$ & \\
\hline Metabolic syndrome & & & & 0.50 \\
\hline Yes & $64(16.3)$ & $34(17.3)$ & $29(14.9)$ & \\
\hline No & $328(83.7)$ & $162(82.7)$ & $166(85.1)$ & \\
\hline
\end{tabular}

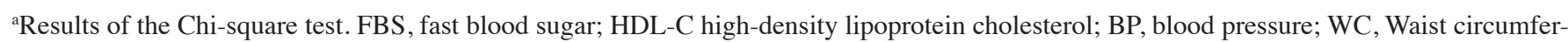
ence; TG, triglycerides.

Table III. Regression analysis for the prediction of metabolic syndrome affliction based on work schedule (shift or day work) adjusted for confounders.

\begin{tabular}{lccccc}
\hline Work schedule & $\begin{array}{c}\text { Unadjusted } \\
\text { OR }(95 \% \mathrm{CI})\end{array}$ & $\begin{array}{c}\text { Model 2 } \\
\text { OR }(95 \% \mathrm{CI})\end{array}$ & $\begin{array}{c}\text { Model 3 } \\
\text { OR (95\% CI) }\end{array}$ & $\begin{array}{c}\text { Model 4 } \\
\text { OR (95\% CI) }\end{array}$ & $\begin{array}{c}\text { Model 5 } \\
\text { OR (95\% CI) }\end{array}$ \\
\hline $\begin{array}{l}\text { Day workers } \\
\text { Shift workers }\end{array}$ & 1 (Reference) & 1 (Reference) & 1 (Reference) & 1 (Reference) & 1 (Reference) \\
\hline
\end{tabular}

Model 1: Single factor logistic regression. Model 2: Adjusted for age (> 35 vs. $\leq 35)$. Model 3: Adjusted for age, educational level, and family income. Model 4: Adjusted for age, educational level, family income, body mass index, and physical activity. Model 5: Adjusted for age, educational level, family income, body mass index, physical activity, work experience, sleep duration, employment, occupational stress, and number of parities. OR, odds ratio; CI, confidence interval.

Logistic regression analysis was used to determine the odds of metabolic syndrome in relation to shift work. Following adjustment for the effects of potential demographical, occupational and medical confounders, the results of the logistic regression analysis demonstrated that the odds of metabolic syndrome among shift workers was nearly two times greater compared with day workers (odds ratio, 1.83; 95\% confidence interval, 0.088-3.79; $\mathrm{P}=0.10$; Table III).

\section{Discussion}

The present study evaluated the association between shift work and metabolic syndrome among women of reproductive age. The results revealed that the prevalence of metabolic syndrome among shift worker participants was $16.3 \%$. However, two previous studies reported that this rate was $22.4 \%$ among healthcare workers in Iran (32) and 19.8\% among patients in a primary healthcare setting in Germany (34). This contradiction may be due the fact that the present study was performed on women aged 18-45 years, while the two previous studies were performed on people from different age groups. Age is a significant risk factor for metabolic syndrome (35), a previous study on 3,024 Iranian women reported that the prevalence of metabolic syndrome was 20\% among women aged 25-34 years and $72 \%$ among women aged 55-64 years (35).

Th present study findings also demonstrated that shift work doubled the risk of metabolic syndrome. Previous studies in Iran $(7,32)$ and Italy (36) have reported the same finding. A 
probable explanation for the higher risk of metabolic syndrome among female shift workers in the current study may be their lower serum HDL level compared to their day worker counterparts. This is in line with the findings of two earlier studies $(8,37)$. The results of a meta-analysis on 74,440 Iranians also revealed that low serum HDL level was the most common predisposing factor for metabolic syndrome (39). Another study on Iranian physicians reported that $>50 \%$ of participants exhibited low serum HDL levels (40). Similarly, a study on Egyptian nurses reported that the level of serum HDL among nurse day worker was twice that of nurse shift workers (38). Lower levels of serum HDL among shift workers may be due to circadian disorders (41). Circadian rhythm causes variations in lipid metabolism (41), whereby periodical alterations in cholesterol and triglycerides over a 24-h period are 31.6 for and $38.5 \%$, respectively (16). Accordingly, shift work may result in dyslipidemia through altering circadian rhythm and sleep-wakefulness cycle (40). Although, a previous study indicated no significant association between serum HDL level and shift work (17).

The present study also demonstrated that sleep quantity and quality among shift workers were significantly less compared with that of day workers, and the majority of shift workers reported that they have inadequate sleep. Sleep has a mediating role in the association between shift work and metabolic syndrome (42). This role is probably due to the negative effects of disturbed sleep among shift workers on circadian rhythm, subsequent alterations in the metabolism of serum lipids and endogenous glucose, and effects on glucose tolerance (42).

The findings in the current study also indicated that a third of participants regularly performed physical activity. Furthermore, the rate of regular physical activity among shift workers was considerably less compared with their day worker counterparts. Similarly, a study on a group of Iranian nurses reported that poor physical activity status' due to their multiple parental and spousal responsibilities, and inadequate time for engagement in physical activity (43). Regular physical activity can reduce the risk of metabolic syndrome through reducing WC and body mass index (44).

None of the participants in the current study reported alcohol consumption and the majority (98\%) did not smoke. Two earlier studies in Iran also reported the same findings $(7,45)$. Unlike the high prevalence of low serum HDL level and abdominal obesity in the present study, only a limited number of participants $(<4 \%)$ suffered from hypertension and diabetes mellitus. These low rates of hypertension and diabetes mellitus in the present study are attributable to the fact that all participants were female and $<45$. Compared with men, women $>50$ years are less likely to develop hypertension (46).

Due to time and financial limitations, the current study was performed using a cross-sectional design. Future studies are recommended to use cohort designs to provide more reliable data on the association between shift work and metabolic syndrome. Additionally, only a third of participants were mother aid, nurse aid, labourer or service workers. The low number of these workers in this study was associated with the limited number of welfare and rehabilitation centers, nursing homes, and industrial female shift workers in the area.

The results of the current study revealed that shift work is associated with greater risk of metabolic syndrome among women of reproductive age. Therefore, metabolic syndrome screening programs should be essential for female shift workers. In addition, the present study suggests that the most important components of metabolic syndrome are low serum HDL level and abdominal obesity, probably due to the limited physical activity intake and high occupational stress of female shift workers. Strategies, including awareness raising, dietary educations, and provision of physical activity facilities at the workplace may reduce the risk of metabolic syndrome among female shift workers, and improve their health status during the reproductive age.

\section{Acknowledgements}

The authors would like to thank Mr. Mohammad Ghasemi (laboratory technician, Shahid Beheshti Hospital, Babol, Iran) who helped collect the study data.

\section{Funding}

The present study was funded by the Health Research Institute in Babol University of Medical Sciences (grant no. 9542537).

\section{Authors' contributions}

MN, AT, MH, AH, AE, FG, FN, BH and MF contributed in the design of the study. MN and $\mathrm{FH}$ performed measurements of biomarkers. MN, AT, MH prepared analyzed the data and the first draft of the manuscript. MN, AT, AE, FG, FN, BH and MF reviewed the manuscript and provided comments. All authors approved the final version of the manuscript.

\section{Availability of data and materials}

All the datasets generated and analyzed in the present study are included in this published manuscript.

\section{Ethics approval and consent to participate}

The Ethics Committee of Babol University of Medical Sciences, Babol, Iran, approved this study (approval no. MUBABOL. HRI.REC.1395.58). Written informed consent was obtained from all participants and they were given the right to voluntarily withdraw from the study.

\section{Patient consent for publication}

Not applicable.

\section{Competing interests}

The authors declare that they have no competing interests.

\section{References}

1. McCullough AJ: Epidemiology of the metabolic syndrome in the USA. J Dig Dis 12: 333-340, 2011.

2. Kawabe Y, Nakamura Y, Kikuchi S, Murakami Y, Tanaka T, Takebayashi T, Okayama A, Miura K, Okamura T and Ueshima H: Relationship between shift work and clustering of the metabolic syndrome diagnostic components. J Atheroscler Thromb 21: 703-711, 2014. 
3. Davila EP, Florez H, Fleming LE, Lee DJ, Goodman E, LeBlanc WG, Caban-Martinez AJ, Arheart KL, McCollister KE, Christ SL, et al: Prevalence of the metabolic syndrome among U.S. workers. Diabetes Care 33: 2390-2395, 2010.

4. de Carvalho Vidigal F, Bressan J, Babio N and Salas-Salvadó J: Prevalence of metabolic syndrome in Brazilian adults: A systematic review. BMC Public Health 13: 1198, 2013.

5. Yu KH, Yi YH, Kim YJ, Cho BM, Lee SY, Lee JG, Jeong DW and Ji SY: Shift work is associated with metabolic syndrome in young female Korean workers. Korean J Fam Med 38: 51-56, 2017.

6. Dalvand S, Bakhshi E, Zarei M, Asl MT and Ghanei R: Prevalence of Metabolic Syndrome in Iran: A systematic review and meta-analysis. MSNJ 5: 1-14, 2017.

7. Mohebbi I, Shateri K and Seyedmohammadzad M: The relationship between working schedule patterns and the markers of the metabolic syndrome: Comparison of shift workers with day workers. Int J Occup Med Environ Health 25: 383-391, 2012.

8. Guize L, Pannier B, Thomas F, Bean K, Jégo B and Benetos A Recent advances in metabolic syndrome and cardiovascular disease. Arch Cardiovasc Dis 101: 577-583, 2008

9. Ginsberg HN and MacCallum PR: The obesity, metabolic syndrome, and type 2 diabetes mellitus pandemic: Part I. Increased cardiovascular disease risk and the importance of atherogenic dyslipidemia in persons with the metabolic syndrome and type 2 diabetes mellitus. J Cardiometab Syndr 4 113-119, 2009.

10. Bolton MM: Sounding the alarm about metabolic syndrome. Nursing 40: 34-40, quiz 40-41, 2010.

11. Cai H, Huang J, Xu G, Yang Z, Liu M, Mi Y, Liu W, Wang H and Qian D: Prevalence and determinants of metabolic syndrome among women in Chinese rural areas. PLoS One 7: e36936, 2012

12. Chandola T, Brunner E and Marmot M: Chronic stress at work and the metabolic syndrome: Prospective study. BMJ 332: 521-525, 2006.

13. Kaur J: A comprehensive review on metabolic syndrome. Cardiol Res Pract 2014: 943162, 2014.

14. Lye MS, Ahmadi N, Khor GL, Hassan STBS, Hanachi P and Delavar AM: Parity and metabolic syndrome in middle-aged Iranian women: A cross-sectional study. Casp J Reprod Med 1: 19-24, 2015.

15. Ye HH, Jeong JU, Jeon MJ and Sakong J: The association between shift work and the metabolic syndrome in female workers. Ann Occup Environ Med 25: 33, 2013.

16. Boivin DB and Boudreau P: Impacts of shift work on sleep and circadian rhythms. Pathol Biol (Paris) 62: 292-301, 2014

17. Kim TW, Jeong JH and Hong SC: The impact of sleep and circadian disturbance on hormones and metabolism. Int J Endocrinol 2015: 591729, 2015

18. Morris CJ, Purvis TE, Hu K and Scheer FA: Circadian misalignment increases cardiovascular disease risk factors in humans. Proc Natl Acad Sci USA 113: E1402-E1411, 2016.

19. Scheer FA, Hilton MF, Mantzoros CS and Shea SA: Adverse metabolic and cardiovascular consequences of circadian misalignment. Proc Natl Acad Sci USA 106: 4453-4458, 2009.

20. Oh JI and Yim HW: Association between rotating night shift work and metabolic syndrome in Korean workers: Differences between 8 -hour and 12-hour rotating shift work. Ind Health 56 40-48, 2018

21. Karlsson BH, Knutsson AK, Lindahl BO and Alfredsson LS: Metabolic disturbances in male workers with rotating three-shift work. Results of the WOLF study. Int Arch Occup Environ Health 76: 424-430, 2003

22. Puttonen S, Viitasalo K and Härmä M: The relationship between current and former shift work and the metabolic syndrome. Scand J Work Environ Health 38: 343-348, 2012.

23. Nazri SM, Tengku MA and Winn T: The association of shift work and hypertension among male factory workers in Kota Bharu, Kelantan, Malaysia. Southeast Asian J Trop Med Public Health 39: 176-183, 2008

24. Akbari H, Mirzaei R, Nasrabadi T and Gholami-Fesharaki M: Evaluation of the effect of shift work on serum cholesterol and triglyceride levels. Iran Red Crescent Med J 17: e18723, 2015.

25. Firouzbakht M, Nikpour M and Tirgar A: The study of impact of employment on gestational age and weight of newborn. Iran J Health Sci 3: 9-14, 2015.

26. Heydarikhayat N, Mohammadinia N, Sharifipour H and Almasy A: Assessing frequency and causes of verbal abuse against the clinical staff. Q J Nurs Manage 1: 70-78, 2012.
27. Tavafi N, Hatami-Zadeh N, Kazem-Nezhad A and Jazayeri A Organizational stressors and related stress intensities in Tehran's comprehensive rehabilitation centers: From the employees' point of view. jrehab 7: 30-34, 2007.

28. Rajaratnam SM, Howard ME and Grunstein RR: Sleep loss and circadian disruption in shift work: Health burden and management. Med J Aust 199: S11-S15, 2013.

29. Nikpour M, Tirgar A, Ebadi A, Ghaffari F, Firouzbakht M and Hajiahmadi M: Development and psychometric evaluation of a women shift workers' reproductive health questionnaire: Study protocol for a sequential exploratory mixed-method study. Reprod Health 15: 22, 2018

30. Sourinejad H, Niyati S and Moghaddam Banaen L: The metabolic syndrome and its components in mid-pregnancy in Tehran. J Urmia Nurs Midwifery Fac 14: 465-473, 2016.

31. Amiri A and Hakimi A: The study of prevalence of metabolic syndrome among nurses of Shahid Mohammadi Hospital of Bandar Abbas city, Iran. jenm 6: 1-8, 2017.

32. Niazi E, Saraei M, Aminian O and Izadi N: Frequency of metabolic syndrome and its associated factors in health care workers. Diabetes Metab Syndr 13: 338-342, 2019.

33. Expert Panel on Detection, Evaluation, and Treatment of High Blood Cholesterol in Adults: Executive summary of the third report of the National Cholesterol Education Program (NCEP) expert panel on detection, evaluation, and treatment of high blood cholesterol in adults (Adult Treatment Panel III). JAMA 285: 2486-2497, 2001

34. Moebus S, Hanisch JU, Aidelsburger P, Bramlage P, Wasem J and Jöckel K-H: Impact of 4 different definitions used for the assessment of the prevalence of the Metabolic Syndrome in primary healthcare: The German Metabolic and Cardiovascular Risk Project (GEMCAS). Cardiovasc Diabetol 6: 22, 2007.

35. Delavari A, Forouzanfar MH, Alikhani S, Sharifian A and Kelishadi R: First nationwide study of the prevalence of the metabolic syndrome and optimal cutoff points of waist circumference in the Middle East: The national survey of risk factors for noncommunicable diseases of Iran. Diabetes Care 32: 1092-1097, 2009.

36. Pietroiusti A, Neri A, Somma G, Coppeta L, Iavicoli I, Bergamaschi A and Magrini A: Incidence of metabolic syndrome among night-shift healthcare workers. Occup Environ Med 67: $54-57,2010$

37. Karlsson B, Knutsson A and Lindahl B: Is there an association between shift work and having a metabolic syndrome? Results from a population based study of 27,485 people. Occup Environ Med 58: 747-752, 2001.

38. Gadallah M, Hakim SA, Mohsen A and Eldin WS: Association of rotating night shift with lipid profile among nurses in an Egyptian tertiary university hospital. East Mediterr Health J 23: 295-302, 2017

39. Daneshpour M, Mehrabi Y, Hedayati M, Houshmand M and Azizi F: A multivariate study of metabolic syndrome risk factors, using factor analysis: Tehran Lipid and Glucose Study. IJEM 8: 139-146, 2006

40. Chiti H, Shakibi E, Soltani Z, Mazloomzadeh S and Mousavinasab S: Prevalence of metabolic syndrome and cardiovascular risk factors among physicians of Zanjan city. ZUMS J 24: 10-20, 2016.

41. Rivera-Coll A, Fuentes-Arderiu X and Díez-Noguera A: Circadian rhythmic variations in serum concentrations of clinically important lipids. Clin Chem 40: 1549-1553, 1994.

42. Kim JY, Yadav D, Ahn SV, Koh SB, Park JT, Yoon J, Yoo BS and Lee SH: A prospective study of total sleep duration and incident metabolic syndrome: The ARIRANG study. Sleep Med 16: $1511-1515,2015$.

43. Kalroozi F, Pishgooie S, Taheriyan A, Khayat S and Faraz R: Health-promoting behaviours and related factors among nurses in selected military hospitals. Journal of Faculty of Nursing, AJA university of Medical Sciences 1: 73-80, 2015.

44. Monteiro CA, Conde WL, Lu B and Popkin BM: Obesity and inequities in health in the developing world. Int J Obes Relat Metab Disord 28: 1181-1186, 2004

45. Fotouhi A, Khabazkhoob M, Hashemi H and Mohammad K: The prevalence of cigarette smoking in residents of Tehran. Arch Iran Med 12: 358-364, 2009

46. Everett B and Zajacova A: Gender differences in hypertension and hypertension awareness among young adults. Biodemogr Soc Biol 61: 1-17, 2015. 